\title{
Off-label prescribing in people with recurrent depressive disorder attending a community mental health service
}

\author{
Chinedu E. Uzoechina, ${ }^{1}$ Pieter Hilvering, ${ }_{1}^{1}$ Cathryn Rogers, ${ }^{1}$ Sinead O'Brien, ${ }^{1}$ Ananth Pullela, \\ Mushtaq Yousafzai, ${ }^{1}$ David J. Meagher ${ }^{1,2}$
}

The Psychiatrist (2011), 35, 84-89, doi: 10.1192/pb.bp.110.030783

${ }^{1}$ St Anne's Day Hospital, Limerick; ${ }^{2}$ University of Limerick Medical School, Ireland

Correspondence to David Meagher (David.Meagher@ul.ie)

First received 7 Apr 2010, final revision 20 Jul 2010, accepted 2 Aug 2010

\begin{abstract}
Aims and method We investigated deliberate and inadvertent off-label prescribing in individuals with recurrent depressive disorder attending a community mental health service.

Results Off-label prescribing occurred in 87 of 226 people with recurrent depressive disorder (38\%) and involved antipsychotic agents (41), maintenance benzodiazepine use (33), antidepressant polypharmacy (28), high-dose antidepressants (19) and use of antidepressants outside of the recommended age range (16). Off-label prescribing was part of a deliberate and documented treatment plan for a half $(n=43)$ of individuals. Participants receiving off-label prescribing had higher total Health of the Nation Outcome Scale (HoNOS) scores, were attending more frequently and were older and had more chronic illness duration. Inadvertent off-label prescribing was related to higher scores on the behavioural disturbance subscale of the HoNOS.
\end{abstract}

Clinical implications Off-label prescribing is a common phenomenon in people with recurrent depressive disorder and relates to greater illness severity and chronicity. Although off-label prescribing is frequently deliberate, in many cases it is undesirable and unplanned.

Declaration of interest Unrelated to this research, D.J.M. has received research grant funding from AstraZeneca Pharmaceuticals.
The use of medicines outside of licensed indications - socalled 'off-label prescribing' - is common in general medicine $^{1}$ and even more frequent in psychiatry where it involves agents from across the psychotropic spectrum. ${ }^{2-4}$ It typically involves four main categories (the four Ds) relating to the disorder treated, patient demographics, dose and duration of treatment. ${ }^{5}$

Off-label prescribing represents a continuum of behaviour from deliberate, targeted activity where some supporting evidence of effectiveness is the motivation for use (e.g. combination antidepressant therapy) $v$. inadvertent off-label activity where the prescriber is unaware that the practice is not licensed. Although the use of agents for licensed indications does not guarantee efficacy or safety, use beyond licensed indications does not imply an absence of evidence and much off-label prescribing is advocated within evidence-based guidelines. ${ }^{6}$ Moreover, off-label prescribing allows for innovative practice that is targeted to the specific needs of an individual. ${ }^{7}$ However, studies have highlighted the risks associated with off-label prescribing 8 emphasising that it is frequently not supported by a robust evidence base. ${ }^{1}$ In view of these concerns, the Royal College of Psychiatrists has made recommendations to guide practice involving unlicensed use of agents in psychiatric practice. $^{2}$ We examined the prevalence of off-label prescribing for a common psychiatric condition (recurrent depressive disorder) in a community mental health service. Relevant participant and illness factors were also explored.

\section{Method}

The study was conducted in the St Anne's Community Mental Health Service, which provides a general adult psychiatry service for a catchment area of approximately 50000 in south-east Limerick. To determine the frequency and clinical factors relevant to unlicensed use of psychotropic agents in people with recurrent depressive disorder, we collected data from the files of all individuals attending over a 3-day period in autumn 2006 regarding demographics, prescribing practice, patterns of clinic attendance (duration, frequency of attendance and missed appointments), and multidisciplinary team contacts (including duration since last contact with responsible consultant psychiatrist). Shared care was defined as attendance with two or more multidisciplinary team members. Diagnoses were made according to ICD-10 
criteria by a single consultant psychiatrist (D.M.). ${ }^{9}$ The characteristics of the service and population have been described in detail previously. ${ }^{10}$

Health and social functioning were assessed with the Health of the Nation Outcome Scales (HoNOS). ${ }^{11}$ These assessments were also made by a single clinician (D.M.) to avoid issues with interrater reliability. ${ }^{12}$ The HoNOS has twelve items and four subscales that rate behaviour, impairment, symptoms and social functioning.

Five categories of off-licence prescribing in individuals with recurrent depressive disorder without a history of psychosis were examined: high-dose antidepressant treatment (i.e. beyond doses provided within the British National Formulary ${ }^{13}$ ); antidepressant polypharmacy; use of antipsychotic agents; maintenance prescribing ( $>4$ weeks) of benzodiazepine agents; and prescribing outside of the recommended age range. In addition, the responsible consultant psychiatrist was asked to review all cases of off-label prescribing and indicate whether this was part of a deliberate and documented treatment plan or undesirable/ inadvertent practice.

Statistical analysis was conducted using SPSS 14 for Windows. We compared individuals receiving off-label prescribing with those who were not, individuals with deliberate $v$. inadvertent off-label prescribing, and specific aspects of off-label prescribing (receiving $v$. not-receiving). Independent $t$-tests (age), Mann-Whitney $U$-tests (HoNOS scores, duration and frequency of attendance/nonattendance, duration since last review by the Royal College of Psychiatrists) and chi-squared tests (gender, frequency of shared care) were used.

\section{Results}

Of the 226 people with recurrent depressive disorder attending the clinic, 87 were treated with off-label prescribing of some sort (38\%), involving 137 instances of
Table 1 Frequency of various off-label prescribing practices $(n=226)$

\begin{tabular}{ll} 
Off-label prescribing practice & $\begin{array}{c}\text { Frequency } \\
n(\%)\end{array}$ \\
\hline Antipsychotic use & $41(18)$ \\
\hline Benzodiazepine maintenance & $33(15)$ \\
\hline Antidepressant polypharmacy & $28(12)$ \\
\hline High-dose antidepressant use & $19(8)$ \\
\hline Outside licensed age range & $16(7)$ \\
\hline
\end{tabular}

off-label prescribing (Table 1). High-dose use (>225 mg) of venlafaxine extended release accounted for all high-dose antidepressant use (19 individuals). Antidepressant polypharmacy consisted mostly (80\%; 23/29) of mirtazapine combined with either venlafaxine $(n=19)$ or duloxetine $(n=4)$. The use of quetiapine accounted for over $50 \%(21 / 41)$ of antipsychotic use, of which 17 people were prescribed a dose of $100 \mathrm{mg}$ a day or less. Other atypicals accounted for most (17/20) of the remainder. Out-of-age-range prescribing involved 2 individuals younger than 18 years and 14 over 65 years of age. Thirty-three people were treated with several types of off-label prescribing simultaneously (range 1-4).

Characteristics of those receiving off-label prescriptions are compared with the remaining individuals with recurrent depressive disorder in Table 2. Significant differences were found in relation to older age, longer duration of attendance and more frequent attendance in the off-label prescribing group, as well as higher total HoNOS scores. There were no significant differences in relation to gender, frequency of non-attendance, HoNOS subscale scores, frequency of shared care and duration since last review by the responsible consultant psychiatrist.

When we considered the relationship between specific aspects of off-label prescribing and participant characteristics, we found that in comparison with the other

\begin{tabular}{|c|c|c|}
\hline & $\begin{array}{l}\text { Receiving off-label } \\
\text { prescription }(n=87)\end{array}$ & $\begin{array}{l}\text { Not receiving off-label } \\
\text { prescription }(n=139)\end{array}$ \\
\hline & \multicolumn{2}{|c|}{ Mean (s.d.) } \\
\hline Age, years ${ }^{\star \star}$ & $46.5(13.0)$ & $40.9(13.2)$ \\
\hline Male/female, \% & $37 / 63$ & $42 / 58$ \\
\hline Duration of attendance, years ${ }^{\star \star \star}$ & $5.3(0.8)$ & $2.9(0.3)$ \\
\hline Number of attendances in the previous year ${ }^{\star \star}$ & $11.1(1.7)$ & $5.6(0.5)$ \\
\hline Number of missed appointments in the previous year & $1.7(0.4)$ & $1.8(0.2)$ \\
\hline Duration since last review by responsible consultant psychiatrist, years & $0.5(1.5)$ & $0.5(0.5)$ \\
\hline Frequency of shared care, \% & 60 & 56 \\
\hline Total HoNOS score* & $7.7(0.5)$ & $6.6(0.4)$ \\
\hline $\begin{array}{l}\text { HoNOS subscales } \\
\text { Behaviour subscale } \\
\text { Impairment subscale } \\
\text { Symptoms subscale } \\
\text { Social subscale }\end{array}$ & $\begin{array}{l}1.8(0.2) \\
0.8(0.1) \\
2.7(0.2) \\
2.3(0.2)\end{array}$ & $\begin{array}{l}1.5(0.2) \\
0.6(0.1) \\
2.4(0.1) \\
2.2(0.2)\end{array}$ \\
\hline
\end{tabular}

HoNOS, Health of the Nation Outcome Scales

${ }^{\star} P<0.05 ;{ }^{\star \star} P<0.01 ;{ }^{\star \star \star} P<0.001$. 
Table 3 Comparison of demographic, service and clinical characteristics of those receiving deliberate and inadvertent off-label prescribing

\begin{tabular}{|c|c|c|}
\hline & $\begin{array}{l}\text { Deliberate off-label } \\
\text { prescribing }(n=43)\end{array}$ & $\begin{array}{l}\text { Inadvertent off-label } \\
\text { prescribing }(n=44)\end{array}$ \\
\hline & \multicolumn{2}{|c|}{ Mean (s.d.) } \\
\hline Age, years & $44.7(11.7)$ & $48.3(14.1)$ \\
\hline Male/female, \% & $25 / 18$ & $30 / 14$ \\
\hline Duration of attendance, years & $5.1(6.9)$ & $5.5(7.1)$ \\
\hline Number of attendances in the previous year & $9.8(9.9)$ & $13.1(10.8)$ \\
\hline Number of missed appointments in the previous year & $1.8(2.5)$ & $1.5(1.5)$ \\
\hline Duration since last review by responsible consultant psychiatrist, years & $0.4(1.5)$ & $0.7(1.2)$ \\
\hline Frequency of shared care, \% & 58 & 62 \\
\hline Total HoNOS score* & $6.7(4.9)$ & $8.6(4.3)$ \\
\hline \multicolumn{3}{|l|}{ HoNOS subscales } \\
\hline Behaviour subscale, & $1.4(1.5)$ & $2.2(2.0)$ \\
\hline Impairment subscale & $0.6(1.1)$ & $1.0(1.4)$ \\
\hline Symptoms subscale & $2.5(1.4)$ & $2.9(1.4)$ \\
\hline Social subscale & $2.2(2.0)$ & $2.5(1.9)$ \\
\hline
\end{tabular}

HoNOS, Health of the Nation Outcome Scales

${ }^{\star} P<0.05$.

participants with recurrent depressive disorder those individuals treated with polypharmacy were significantly older $(P=0.01)$ and had a higher frequency of attendance $(P=0.02)$. Antipsychotic use was associated with a longer duration $(P=0.006)$, higher frequency of attendance $(P<0.001)$ and higher total HoNOS and behaviour subscale scores (both $P=0.02$ ). The prescription of maintenance benzodiazepines was more common in females $(P=0.03)$ and was associated with a longer duration $(P=0.02)$, higher frequency of attendance $(P=0.02)$, and higher total HoNOS $(P=0.01)$ and behaviour subscale scores $(P=0.008)$. Highdose antidepressant treatment and use of antidepressants beyond the appropriate age category were not associated with a significant difference in any of the parameters.

Off-label prescribing was further divided into deliberate $(n=91 ; 68 \%) \quad v$. undesirable/inadvertent $(n=46)$ according to whether the practice was part of a documented treatment plan. Forty-four people had at least one aspect of prescribing that was inadvertently off label and this subgroup is compared with those who had exclusively deliberate off-label prescribing in Table 3. These subgroups were largely similar in relation to demographic and clinical variables but with significantly higher scores for total HoNOS $(P=0.03)$ and a trend for greater behavioural problems $(P=0.07)$ in the inadvertent group.

\section{Discussion}

\section{Frequency of off-label prescribing}

This study focused on five aspects of off-label prescribing for the commonest clinical diagnosis (recurrent depressive disorder) occurring in people attending a community mental health service. We found that off-label prescribing was common and related to a range of patient demographic and clinical variables. It was frequently part of a documented and deliberate treatment plan but in a significant minority of cases reflected inadvertent or undesirable practice.
Previous work in this area has focused on prescribing in acute in-patient settings and/or the use of specific drugs in particular populations. Douglas-Hall and colleagues ${ }^{14}$ studied prescribing patterns in acute psychiatric in-patients from 14 National Health Service trusts and identified that $7.5 \%$ of prescriptions involved off-label use of drugs, whereas Hodgson \& Belgamwar ${ }^{4}$ found that use of antipsychotics was off label in $40 \%$ of those treated within specialist psychiatry services. European studies in community-based settings suggest that one-half to twothirds of antipsychotic use is off label. ${ }^{15,16}$ Similarly, in one study from the USA off-label prescribing in combat veterans comprised $43 \%$ of atypical antipsychotic use. ${ }^{17}$

\section{Factors associated with off-label prescribing}

Diagnostic factors are a key determinant of drug use, such that the licensed indications are often dictated by the initial use of an agent even though evidence can emerge for use in other unlicensed indications. Innovation in pharmacotherapy requires wider clinical use but often remains off label because there is limited benefit for manufacturers to go through the onerous process of seeking additional licensed indications, especially with agents that have a limited remaining duration of patent. As such, a common disorder such as recurrent depressive disorder that is prone to treatment resistance and often requires innovative approaches to pharmacotherapy commonly results in offlabel use of drugs. Leslie and colleagues found that common diagnoses for off-label use of antipsychotics were posttraumatic stress disorder (42\%) and minor (39\%) or major (23\%) depression. ${ }^{18}$

A number of previous studies have identified higher rates of off-label prescribing in older age groups, ${ }^{19,20}$ perhaps reflecting greater treatment resistance or more chronic illness. In our study we also found a positive correlation between older age and off-label prescribing in general and specifically in relation to the frequency of 
polypharmacy. The increased frequency of these practices in older people is a cause for concern because associated physical risks are more pronounced in older individuals.

A strength of this work is the inclusion of a measure of symptom profile within the diagnostic category of recurrent depressive disorder. Previous work has focused on diagnostic categories as predictors of off-label prescribing but without consideration of the role of particular clinical variants within these categories. ${ }^{4,18}$ Other work linked particular practices such as polypharmacy to illness severity. ${ }^{21}$ The observed cross-sectional associations do not imply causality as effective use of off-label prescribing is likely to diminish symptoms, although some of the observed associations are symptoms that could conceivably be caused by off-label prescribing (e.g. paradoxical disinhibition with benzodiazepines). Nevertheless, it was apparent that off-label prescribing occurred more frequently in individuals with a greater burden of clinical problems (as per the HoNOS) and that, in particular, offlabel use of antipsychotics and benzodiazepines was related to higher scores on the behavioural subscale of the HoNOS that includes problems with agitation, deliberate self-harm and substance misuse. It seems more likely that the use of these agents represents a response to more complex presentations of depressive illness that are complicated by behavioural disturbances and/or comorbid substance misuse.

\section{Categories of off-label prescribing}

The relative frequency of different aspects of off-label prescribing is uncertain but is likely to vary considerably according to treatment settings and populations studied. In a postal survey of psychiatrists, Lowe-Ponsford \& Baldwin found that off-label prescribing was as a result of use of agents in diagnoses without a licensed indication in $50 \%$ of cases, with variations in dose (19\%) and age (12\%) also common. ${ }^{22}$ Our work highlights a broad range of reasons for prescribing off label within a specific diagnostic category, reflecting the particular challenges of individuals with comorbid anxiety and treatment-resistant illness where high-dose or combination/augmentation strategies were applied.

\section{Antipsychotics}

The use of antipsychotic agents in the management of depressive illness has become increasingly popular in recent years as a result of a gathering evidence base. Nelson \& Papakostas conducted a meta-analysis of 16 randomised controlled trials of atypical antipsychotics' use in treatmentresistant, non-psychotic, unipolar major depression and found significant benefits compared with placebo but with higher discontinuation rates due to adverse effects. ${ }^{23}$ Hodgson \& Belgamwar found that $18 \%$ of off-label use antipsychotics in secondary care attenders in north Staffordshire was for affective disorder diagnoses. ${ }^{4}$ Similarly, Leslie $e t a l^{18}$ studied off-label use of antipsychotics in the US Department of Veteran Affairs healthcare system and found that affective disorders and post-traumatic stress disorder were the commonest diagnoses associated with $23 \%$ of off-label prescribing in people with major depressive disorder. Doses were typically lower than those suggested for psychotic illness.
The prevalence of off-label use of antipsychotics in our cohort was similar (18\%) to these studies. We were also able to document the agents used, which included the use of lowdose quetiapine as an hypnotic as well as antipsychotic augmentation for more resistant illness.

\section{Antidepressant polypharmacy and use in high dose}

Although the use of antidepressants in combination is not highlighted as unlicensed use in the Royal College of Psychiatrists report, ${ }^{2}$ it is not included within licensed indications and warrants the same approach to patient information and documentation of risk/benefit ratio as other practices with uncertain prescribing status. Moreover, although there is a gathering literature to support such strategies in treatment-resistant illness, they can convey an increased potential for adverse drug interactions. Future guidelines regarding the use of agents beyond licensed indications would benefit from inclusion of such practices. Previous studies have not explored the frequency of such practice but the noradrenergic and specific serotonergic antidepressant/serotonin and noradrenaline reuptake inhibitor combination is a particular strategy that has been used to effect in our service. ${ }^{24,25}$

Similarly, high-dose venlafaxine treatment is supported by an evidence base and reflects deliberate prescribing. ${ }^{26}$ However, the licensed dose range for the slow-release form has only recently been increased to that of the regular venlafaxine. The slow-release form is preferred within our service due to superior tolerability but because of this licensing issue it was technically off label. Recent increases in the licensed dose range for the slow-release form means that much of the high-dose treatment documented in this work would no longer be considered off label, highlighting the evolving nature of licensed prescribing.

\section{Benzodiazepines}

Benzodiazepines are licensed for the short-term treatment of anxiety but are not advocated in longer-term treatment or in mood disorders because of the risks of dependence, daytime sedation, cognitive impairment and falls. The reduction of benzodiazepine use has been a specific target within the St Anne's service for many years, ${ }^{27-29}$ such that the documented rate in this study may be lower than elsewhere. However, similar to others, ${ }^{30}$ we have found that for a small percentage of individuals maintenance use of benzodiazepines persists despite our best efforts to manage with other approaches. Maintenance benzodiazepine use occurred in individuals with higher scores on the behavioural subscale of the HoNOS, perhaps indicating that benzodiazepines are being used for more complex and challenging presentations of recurrent depressive disorder.

\section{Management of off-label prescribing}

The high rate of off-label prescribing ( $38 \%$ of individuals), with over two-thirds of cases indentified as deliberate and goal directed reflects the shortcomings of licensing norms in addressing the needs of real-world patients. However, although much off-label prescribing was targeted, there remained a considerable amount of inadvertent practice, highlighting the need for continued vigilance and education about such practices. In contrast, Radley et $a l^{1}$ studied 
treatment patterns for 160 commonly prescribed drugs with the National Disease and Therapeutics Index and found that off-label prescribing comprised $21 \%$ of prescribing and that the vast majority (96\%) of off-label use of psychotropics had little or no scientific support.

Royal College of Psychiatrist guidelines suggest that where off-label prescribing occurs it should be closely monitored. ${ }^{2}$ It was reassuring that people receiving off-label prescribing attended more frequently and did not have a higher frequency of missed appointments. This may indicate an elevated level of monitoring of off-label prescribing and/ or more frequent attendance because of higher morbidity levels in those receiving off-label prescribing. More frequent attendance in those receiving maintenance benzodiazepines may reflect a reluctance of clinicians to provide long-term prescriptions or greater motivation for clinic attendance because of the addictive qualities of these agents. Whatever the reason, greater supervision of such individuals is highly desirable.

\section{Limitations}

Although many aspects of the St Anne's service make it a relatively representative population of individuals attending a community-based service, the population have previously participated in studies focused on the quality of prescribing practices, including the use of benzodiazepines, high-dose medications and polypharmacy. As a consequence, there may be a disproportionate awareness among clinicians of off-label prescribing in this service. ${ }^{27-29}$ In addition, the inclusion of clinical ratings is a valuable aspect of this work but the cross-sectional design of the study limits the interpretation of HoNOS scores such that they may not be causally related to prescribing practice. Future work addressing the clinical and economic effectiveness of offlabel prescribing can further illuminate this issue.

\section{Acknowledgements}

We thank the Community Mental Health Team at St Anne's Day Hospital, all of whom contributed to data collection and analysis.

\section{About the authors}

Chinedu E. Uzoechina is registrar in psychiatry and Pieter Hilvering is senior registrar in child and adolescent psychiatry, Limerick Mental Health Services; Cathryn Rogers is senior registrar in liaison psychiatry, Beaumont Hospital, Dublin; Sinead O'Brien is consultant psychiatrist, Mercy University Hospital, Cork; Ananth Pullela and Mushtaq Yousafzai are consultant psychiatrists, Limerick Mental Health Services; David J. Meagher is professor of psychiatry, University of Limerick Medical School and consultant psychiatrist, Limerick Mental Health Services.

\section{References}

1 Radley DC, Finkelstein SN, Stafford RS. Off-label prescribing among office-based physicians. Arch Intern Med 2006; 166: 1021-6.

2 Royal College of Psychiatrists. Use of Licensed Medicines for Unlicensed Applications in Psychiatric Practice (College Report CR142). Royal College of Psychiatrists, 2007.
3 Harrington $M$, Lelliot $P$, Paton C, Okocha C, Duffett R, Sensky T. The results of a multi-centre audit of the prescribing of antipsychotic drugs for in-patients in the UK. Psychiatr Bull 2002; 26: 414-8.

4 Hodgson R, Belgamwar R. Off-label prescribing by psychiatrists. Psychiatr Bull 2006; 30: 55-7.

5 Baldwin DS, Kosky N. Off-label prescribing in psychiatric practice. Adv Psychiatr Treat 2007; 13: 414-22.

6 Taylor D, Paton C, Kerwin R. Maudsley Prescribing Guidelines, 9th edn. Informa Healthcare, 2007.

7 Stafford RS. Regulating off-label drug use - rethinking the role of the FDA. N Engl J Med 2008; 358: 1427-9.

8 Jonville-Béra AP, Béra F, Autret-Leca E. Are incorrectly used drugs more frequently involved in adverse drug reactions? A prospective study. Eur J Clin Pharmacol 2005; 61: 231-6.

9 World Health Organization. The ICD-10 Classification of Mental and Behavioural Disorders: Clinical Descriptions and Diagnostic Guidelines. WHO, 1992

10 Meagher D, O'Brien S, Pullela A, Oshun A, Brosnan P. Multidisciplinary activities in a community mental health service: relationship to Health of the Nation Outcome Scale scores and diagnosis. Psychiatr Bull 2009; 33: $172-5$

11 Wing JK, Beevor AS, Curtis RH, Park SB, Hadden S, Burns A. Health of the Nation Outcome Scales (HoNOS). Research and development. $\mathrm{Br} J$ Psychiatry 1998; 172: 11-8.

12 Bebbington P, Brugha T, Hill T, Marsden L, Window S. Validation of the Health of the Nation Outcome Scales. Br J Psychiatry 1999; 174: 389-94.

13 British Medical Association, Royal Pharmaceutical Society of Great Britain. British National Formulary, 58th edn. BMJ Books, Pharmaceutical Press, 2009.

14 Douglas-Hall P, Fuller A, Gill-Banham S. An analysis of off-licence prescribing in psychiatric medicine. Pharm J 2001; 267: 890-1.

15 Barbui C, Ciuna A, Nosé M, Patten SB, Stegagno M, Burti L, et al. Offlabel and non-classical prescriptions of antipsychotic agents in ordinary in-patient practice. Acta Psychiatr Scand 2004; 109: 275-8.

16 Weiss E, Hummer M, Koller D, Ulmer H, Fleischhacker WW. Off-label use of antipsychotic drugs. J Clin Psychopharmacol 2000; 20: 695-8.

17 Rosenheck R, Leslie D, Sernyak M. From clinical trials to real-world practice: use of atypical antipsychotic medication nationally in the Department of Veteran Affairs. Med Care 2001; 39: 302-8.

18 Leslie DL, Mohamed S, Rosenheck RA. Off-label use of antipsychotic medications in the Department of Veteran Affairs health care system. Psychiatr Serv 2009; 60: 1175-81.

19 Chen H, Reeves JH, Fincham JE, Kennedy WK, Dorfman JH, Martin BC. Off-label use of antidepressant, anticonvulsant, and antipsychotic medications among Georgia medicaid enrollees in 2001. J Clin Psychiatry 2006; 67: 972-82.

20 Kamble P, Sherer J, Chen H, Aparasu R. Off-label use of second generation antipsychotic agents among elderly nursing home residents. Psychiatr Serv 2010; 61: 130-6.

21 Mojtabai R, Olfson M. National trends in psychotropic medication polypharmacy in office-based psychiatry. Arch Gen Psychiatry 2010; 67: 26-36.

22 Lowe-Ponsford F, Baldwin D. Off-label prescribing by psychiatrists. Psychiatr Bull 2000; 24: 415-7.

23 Nelson JC, Papakostas GI. Atypical antipsychotic augmentation in major depressive disorder: a meta-analysis of placebo-controlled randomised trials. Am J Psychiatry 2009; 166: 980-91.

24 Meagher D, Hannan N, Leonard M. Duloxetine-mirtazapine combination in depressive illness: the case for Limerick 'rocket fuel'. Irish J Psychol Med 2006; 23: 116-8.

25 Hannan N, Hamzah Z, Akinpeloye HO, Meagher D. Venlafaxinemirtazapine combination in the treatment of persistent depressive illness. J Psychopharmacol 2007; 21: 161-4.

26 Thase ME, Shelton RC, Khan A. Treatment with venlafaxine extended release after SSRI nonresponse or intolerance: a randomized 
comparison of standard- and higher-dosing strategies. J Clin Psychopharmacol 2006; 26: 250-8.

27 Raju B, Meagher D. Patient-controlled benzodiazepine dose reduction in a community mental health service. Irish J Psychol Med 2005; 22: 42-5.

28 Moran M, Raju B, Saunders J, Meagher D. Achieving evidence-based prescribing practice in an adult community mental health service. Psychiatr Bull 2006; 30: 51-5.
29 Meagher D, Pullela A, Meisinger M, Geaney N, O'Brien S. Five-year follow up of an evidence-based prescribing intervention. Psychiatr Bull 2008; 32: 183-6.

30 Haw C, Stubbs J. Benzodiazepines: a necessary evil? A survey of prescribing at a specialist UK psychiatric hospital. J Psychopharmacol 2007; 21: 645-9.

\title{
From home treatment to crisis resolution: the impact of national targets
}

\author{
Judy Harrison, ${ }^{1}$ Sheethal Rajashankar, ${ }^{1}$ Simon Davidson ${ }^{1}$
}

The Psychiatrist (2011), 35, 89-91, doi: 10.1192/pb.bp.110.029876

'Manchester Mental Health and Social Care Trust, Manchester

Correspondence to Judy Harrison (judy.harrison@mhsc.nhs.uk)

First received 25 Feb 2010 , final

revision 9 Jul 2010, accepted

6 Aug 2010
Aims and method The home treatment service in central Manchester was established in 1997 to provide an alternative to in-patient care: referrals were only taken from secondary care services. In order to meet national crisis resolution and home treatment (CRHT) activity targets, referral routes were extended to primary care from 2008. To examine the impact of these changes, details of all referrals to the service were collected for a 6-month period in 2008/2009. Referral sources, demographic details and diagnosis were compared with similar data from 2005.

Results There was a marked increase in the number of individuals accepted by the service in 2008/2009 with a corresponding reduction in duration of contact. Primary care referrals were not accepted in 2005 but accounted for $20 \%$ of people treated in $2008 / 2009$. This was mirrored by a change in diagnostic profile, with the proportion of individuals with mild to moderate illness increasing from 25 to 50\%. In 2005, 70\% of individuals treated had complex care needs compared with 39\% in 2008/2009.

Clinical implications The strict imposition of numerical activity targets can have a significant impact on service delivery. Although more individuals have been treated under the new arrangements, the emphasis has shifted away from the intensive care of those with severe mental illness.

Declaration of interest None.
The development of crisis resolution and home treatment (CRHT) teams has been a central tenet of English mental health policy since $2000 .^{1}$ Although the policy implementation guidance ${ }^{2}$ was highly prescriptive in relation to staffing and operation of CRHT teams, there were relatively few such teams in operation in the UK at that time. Since then there has been unprecedented investment and growth in CRHT services, with the National Audit Office reporting a $400 \%$ increase in spend on CRHT between 2002 and 2007, with 343 teams in operation across England in 2006/2007. ${ }^{3}$ These new teams have been intensively performance managed, with each expected to provide a threshold number of episodes of care as part of the local primary care trust annual targets.

Although there is good research evidence that wellresourced teams can reduce length of stay and hospital admission rates, ${ }^{4,5}$ concern has also been expressed that the purely numerical activity targets can result in a shift away for the care of the most severely ill in order to maximise throughput. ${ }^{3}$ The lack of medical involvement in services has also been cause for concern, with the National Audit Office $^{3}$ reporting that almost a third of teams have no dedicated psychiatrist and more than $50 \%$ have less than a half-time equivalent.

Manchester was one of the first centres to develop an acute home treatment service ${ }^{6}$ and repeated activity audits during the past 10 years have provided a unique opportunity to explore in more detail the impact of national targets. The home treatment service in central Manchester was established in 1997, with a focus on providing a 24-h alternative to in-patient care for those with acute or severe mental illness. ${ }^{6}$ The staffing levels and method of operation 